\title{
O Suporte das Incubadoras Brasileiras na Gestão de Custos das Empresas Incubadas
}

\author{
Fabiano Maury Raupp \\ E-mail: fabianoraupp@hotmail.com
}

\section{RESUMO}

O estudo apresenta uma investigação sobre o suporte das incubadoras brasileiras na gestão de custos das empresas incubadas. Estudo descritivo, de natureza quantitativa, foi realizado por meio de pesquisa survey. A população corresponde a 359 incubadoras associadas à ANPROTEC. O questionário foi enviado por e-mail aos coordenadores das incubadoras, obtendo-se o retorno de 157 coordenadores. As incubadoras brasileiras disponibilizam suporte na gestão de custos das empresas incubadas por meio de capacitação, participação em eventos e disponibilização de tecnologias. A minoria das empresas incubadas possui formalização dos controles de custos. Quanto às formas de identificação de custos, a unidade de produto correspondeu à maioria das indicações, sendo que as informações de custos são mais utilizadas em decisões de vendas.

Palavras-chave: Gestão de custos. Empresas Incubadas. Incubadoras brasileiras.

\section{The Support of the Brazilian Incubators in the Cost Management of Companies} Incubated

\begin{abstract}
The study presents an investigation on the support of the brazilian incubators in the cost management of companies incubated. A descriptive, quantitative study was conducted by survey research. The population amounts to 359 incubators associated with ANPROTEC. The questionnaire was sent by e-mail to the incubators coordinators, having the return of 157 . Brazilian incubators provide support in costs management of the incubated companies through training, participation in events and availability of technologies. The minority of the incubated companies have cost control formalization. Regarding to how the costs are identified, the output unit accounted for most indications, and cost information are more used in sales decisions.
\end{abstract}

Keywords: Cost Management. Incubated Companies. Brazilian Incubators.

\section{INTRODUÇÃO}

No atual ambiente empresarial, permeado de constantes transformações, a gestão de custos passou a ser considerada um elemento fundamental na busca pela 
competitividade das organizações. Em incubadoras de empresas esta situação também deve ser considerada, uma vez que estão voltadas ao nascimento e desenvolvimento de empreendimentos nelas instalados.

Particularmente em relação às micro e pequenas empresas, estas nem sempre estão preparadas para os efeitos do aumento da competitividade, haja vista que possuem uma estrutura empresarial mais simples, se comparadas às médias $\mathrm{e}$ grandes empresas. Além disso, nem sempre são gerenciadas por pessoas com experiência e/ou formação para exercer essa função. Apesar disso, representam um importante segmento dentro do mercado.

Fonseca e Kruglianskas (2000) explicitam que as pequenas empresas passaram a representar, no final do século 20 , a maioria das unidades de negócio em todos os países do mundo, fossem industrializados, em desenvolvimento ou subdesenvolvidos. Estas passaram a responder por cerca de $50 \%$, quando não mais do valor da produção e a reter mais da metade do total dos postos de trabalho.

Observam que, apesar de sua importância, este segmento empresarial apresenta um perfil de debilidades. As principais debilidades estruturais das micro e pequenas empresas são: baixa intensidade de capital, capacidade de financiamento restrita, precariedade da função gerencial, baixa qualificação dos recursos humanos, precariedade da função tecnológica, falta de planejamento a longo prazo, e pequeno poder de barganha com parceiros comerciais.

Um dos mecanismos utilizados por pessoas que iniciam negócios sob a forma de micro e pequenas empresas, para reduzir a instabilidade, é o de se instalar em incubadoras de empresas. As incubadoras procuram promover essa redução por meio do suporte administrativo, financeiro e de estrutura, que é disponibilizado às empresas incubadas durante o processo de incubação.

Apoiado nestas premissas percebe-se a crescente importância das incubadoras no desenvolvimento regional e nacional, subsidiando, principalmente, o nascimento e parte do crescimento de micro e pequenas empresas. Considerandose o ciclo de vida das organizações, verifica-se que algumas das fases iniciais destas empresas podem ser concebidas em uma incubadora.

Relacionando as várias iniciativas proporcionadas pelas incubadoras, na geração de novos empreendimentos, com a mortalidade precoce de muitas 
empresas, acredita-se que as empresas incubadas tendem a estar melhor preparadas quando se inserem no mercado de forma autônoma e, por conseguinte, evitam a mortalidade na fase inicial do empreendimento. Tais questões reforçam a permanência de empresas incubadas no mercado e a criação de novas redes de incubadoras no país.

Contudo, não se tem encontrado pesquisas que investiguem a gestão de custos nas empresas incubadas. Assim, o objetivo do estudo consiste em investigar o suporte das incubadoras brasileiras na gestão de custos das empresas incubadas.

Para tanto, inicia-se fazendo uma incursão teórica nos fundamentos que sustentam o estudo, abordando incubadoras de empresas e gestão de custos. $\mathrm{Na}$ sequência, apresenta-se a metodologia da pesquisa. Em seguida, procede-se à descrição e análise dos dados coletados. Por último, apresentam-se as considerações finais do estudo realizado.

\section{INCUBADORAS DE EMPRESAS}

As micro e pequenas são de vital importância, tanto no que concerne à sua contribuição ao crescimento econômico como à geração de novos postos de trabalho. Assim, o governo, juntamente com entidades de vários setores públicos e privados, tem envidado esforços para criação de mecanismos que possam apoiar este segmento de empresas.

Dentre os mecanismos de apoio, destaca-se a atuação das incubadoras de empresas, que, além de incentivar o desenvolvimento de negócios de pequeno porte, buscam capacitar os empreendedores para gerir o seu empreendimento. Acredita-se que a empresa instalada em uma incubadora tende a apresentar maiores probabilidades de sobrevivência quando inserida no mercado, comparativamente com aquelas que não tiveram a mesma oportunidade.

Em relação às incubadoras de empresas, conforme destacam Fonseca e Kruglianskas (2000), originalmente a idéia esteve associada ao propósito de estimular o surgimento de negócios resultantes de projetos tecnológicos desenvolvidos no interior dos centros de pesquisa universitários ou não. O conceito criado foi o de incubadoras tecnológicas, voltadas para apoiar o nascimento e o 
fortalecimento das chamadas empresas de base tecnológica.

Mais recentemente, principalmente a partir dos anos 90, as iniciativas diversificaram-se. Assim, passou a ganhar espaço a idéia de incubadoras mistas, com unidades criadas por governos locais, para estimular o crescimento econômico e gerar empregos. Independente de um tipo ou outro, de acordo com Dornelas (2002), a incubadora de empresas é definida como um mecanismo - mantido por entidades governamentais, universidades, grupos comunitários etc. - de aceleração do desenvolvimento de empreendimentos (incubados ou associados), por meio de um regime de negócios, serviços e suporte técnico compartilhado, além de orientação prática e profissional.

As incubadoras, conforme Hackett e Dilts (2004), são espaços compartilhados que proporcionam às novas empresas recursos tecnológicos e organizacionais; sistemas que criam valor agregado; monitoramento e ajuda empresarial, com o objetivo de facilitar o sucesso dos novos empreendimentos, reduzindo ou eliminando o custo de potenciais falhas que se apresentam na criação do negócio e que são controladas no período de incubação. Os novos empreendimentos recebem apoio do governo, comunidades locais e investidores privados, com o intuito de superar determinadas dificuldades iniciais, tendo uma perspectiva de sucesso.

Infere-se do exposto que uma incubadora oferece às empresas incubadas diversas facilidades, desde apoio administrativo até auxílio na obtenção de linhas de financiamento. Mediante a infra-estrutura disponibilizada, as incubadoras de empresas contribuem para que possa ocorrer a consolidação das empresas incubadas.

Conforme Baêta (1999), as incubadoras implicam em condições bastante específicas e não se esgotam numa simples criação de empresas, mas também há o monitoramento para estimular o processo de inovação. As incubadoras promovem oportunidades para o desenvolvimento tecnológico do processo produtivo e oferecem aos novos empreendedores, além de espaço físico e os serviços de escritório, o apoio administrativo, aconselhamento e consultoria gerencial e de marketing.

Sob uma perspectiva mais ampla, a missão das incubadoras é a de fornecer serviços e recursos compartilhados, em termos de profissionais competentes, 
instalações adequadas e infra-estrutura administrativa e operacional à disposição das empresas incubadas. Estes organismos criam um ambiente favorável à consolidação de novos empreendimentos, através de algumas iniciativas, como: fornecer apoio técnico e gerencial às empresas incubadas, promover e acelerar a consolidação de empresas, estimular o espírito empreendedor, desenvolver ações associativas e compartilhadas, reduzir custos para o conjunto das empresas e seus parceiros, buscar novos apoios e parcerias para as empresas, divulgar as empresas e seus produtos e participar de outras redes (AMATO NETO, 2000).

As incubadoras de empresas, que têm sido implementadas em todos os países desenvolvidos e em desenvolvimento, apresentam-se, atualmente, como um locus adequado para abrigar e apoiar as micro e pequenas empresas. Ao prover instalações físicas adequadas e de qualidade, com serviços de apoio compartilhados e com aconselhamento sobre o funcionamento do mercado, sobre tecnologias e seus aspectos, e sobre viabilidade de apoio financeiro, as incubadoras buscam explorar e potencializar os recursos existentes. Elas procuram, ainda, criar um ambiente favorável ao surgimento e fortalecimento de novos empreendimentos, ou seja, objetivam tornar as suas incubadas em empresas graduadas bem sucedidas (VEDOVELLO, FIGUEIREDO, 2005).

Quanto às tipologias de incubadoras, as mais comuns são: incubadoras de empresas de base tecnológica, incubadoras de empresas de setores tradicionais e incubadoras mistas. As incubadoras de empresas de base tecnológica contemplam empreendimentos relacionados ao desenvolvimento de tecnologia, como empresas de informática, biotecnologia, química fina, mecânica de precisão e novos materiais. As incubadoras de setores tradicionais abrigam empresas orientadas para o desenvolvimento econômico, como mecânica, eletrônica, confecção, alimentos, agroindústria, sendo que normalmente dependem do suporte de órgãos e entidades como prefeituras, governo do Estado ou associações comerciais, industriais e agrícolas. As incubadoras mistas, como o próprio nome demonstra, abrigam ao mesmo tempo empresas de base tecnológica e empresas de setores tradicionais.

As incubadoras não atuam sozinhas, desenvolvem parcerias com vários outros organismos, como governo, prefeituras, entidades com ou sem fins lucrativos, agentes financeiros, entre outros. Por meio deste apoio, as incubadoras conseguem 
atingir seu objetivo principal: promover o desenvolvimento e crescimento de micro e pequenas empresas.

O Brasil tem-se destacado pelo crescimento contínuo do número de incubadoras. O Panorama de Incubadoras de Empresas e Parques Tecnológicos, pesquisa realizada anualmente pela ANPROTEC, em parceria com o SEBRAE, busca retratar e documentar a situação do movimento de incubação brasileiro. $\mathrm{Na}$ Figura 1, apresenta-se a evolução do movimento brasileiro de incubadoras.

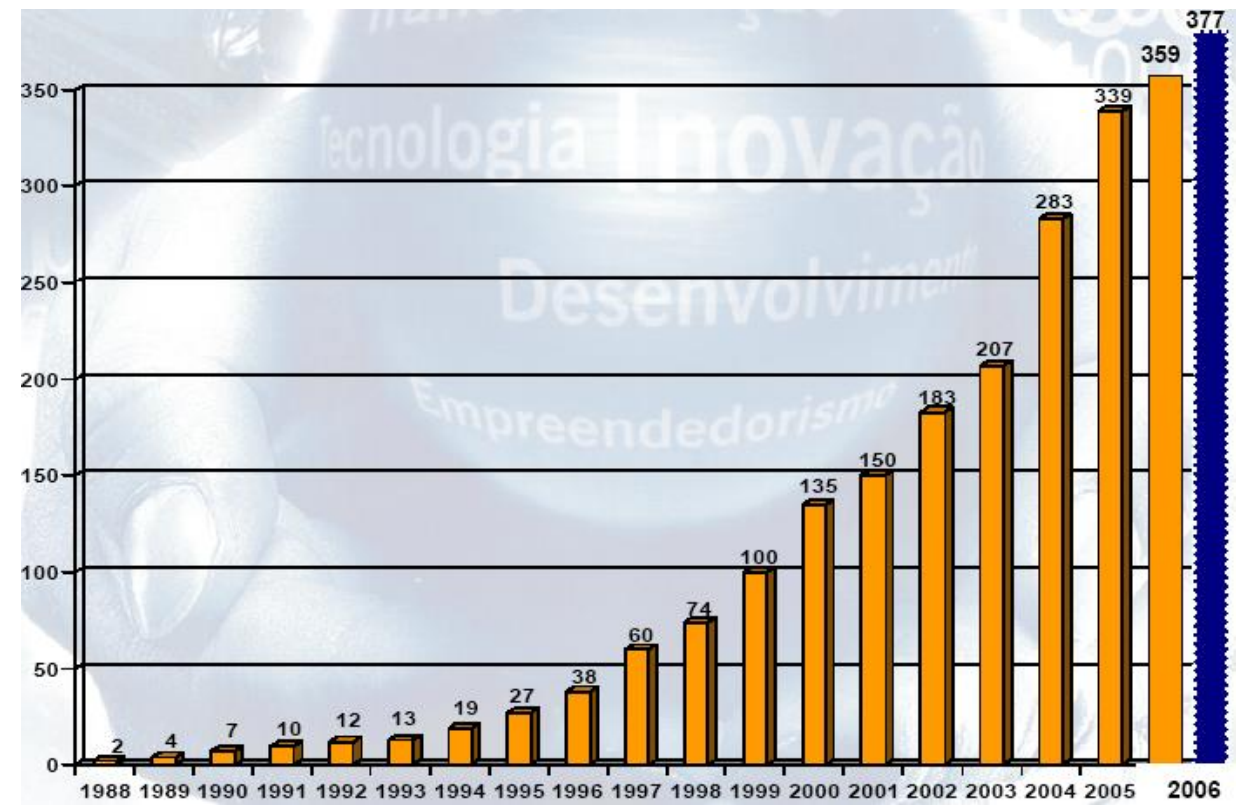

Figura1: Evolução do movimento brasileiro de incubadoras Fonte: ANPROTEC (2010).

É expressivo o crescimento de incubadoras em operação ao longo dos anos. Nos últimos 10 anos houve um crescimento de aproximadamente $787 \%$ no número de incubadoras. As incubadoras de empresas brasileiras, com o passar dos anos, cresceram não apenas em número, mas, também, em grau de complexidade. Além de novas estruturas, foram surgindo novos tipos de incubadoras que não fossem de base tecnológica.

Portanto, as incubadoras de empresas são entidades destinadas a amparar o desenvolvimento de pequenos negócios por meio de um rol de suportes colocados à disposição dos empreendedores. Suas características estão alicerçadas nas necessidades de empresas desse porte, desde o aspecto administrativo e operacional ao financeiro. 


\section{IMPORTÂNCIA DA GESTÃO DE CUSTOS EM EMPRESAS INCUBADAS}

A Contabilidade de Custos se originou da Contabilidade Financeira, tendo como finalidade a avaliação de estoques na indústria. Segundo Martins (2003), seus princípios derivam desse propósito e, por este motivo, nem sempre conseguem atender com completeza suas outras duas mais recentes atribuições: controle dos custos e suporte na tomada de decisão. Estes novos campos deram horizontes mais amplos à Contabilidade de Custos.

Desse modo, nas empresas em que as informações de custos são usadas para desenvolver estratégias que visam à obtenção de vantagem competitiva e um melhor gerenciamento dos custos, exige-se um enfoque externo e interno à empresa. Conforme Porter (1989), mudanças na tecnologia, necessidades do comprador, políticas governamentais ou infra-estrutura do país criam diferenças importantes na posição competitiva entre empresas de diferentes países ou tornam mais significativas as vantagens de uma estratégia global.

A compreensão da estrutura de custos de uma empresa pode avançar na busca de vantagens competitivas. Megliorini (2007) explicita que a rápida evolução tecnológica que vem ocorrendo desde o final do século XX, em resposta a um ambiente competitivo mais intenso, tem obrigado as empresas a reformular continuamente suas estratégias e a se preocupar cada vez mais com a gestão de custos.

No atual contexto empresarial, são necessárias informações de custos cada vez mais detalhadas e aprimoradas. Os gestores necessitam de informações de custos da cadeia de valor global, desde o fornecedor até o pós-venda, uma vez que custos não compatíveis com as estratégias dos clientes podem estar fora da empresa envolvida na negociação. Por exemplo, é possível que o desafio seja reduzir custos junto aos fornecedores, como também pode ser nos distribuidores dos produtos. Por isso da importância de se analisar a cadeia de valor como um todo, podendo aumentar a vantagem competitiva da indústria.

Assim, as empresas estão se dedicando à melhoria de alguns aspectos críticos da gestão dos custos, tais como: melhorar o desempenho de produtos e 
processos, atribuir maior atenção às exigências do mercado, promover uma melhor gestão estratégica e operacional de suas áreas de responsabilidade, fazer parcerias com fornecedores e acompanhar seu desempenho, negociar alíquotas tributárias com governos, entre outros aspectos. Denota-se que a gestão de custos implica gerenciar fatores internos e externos das empresas.

Blocher, Chen, Cokins e Lin (2007) afirmam que, seja qual for o setor da empresa, esta deve saber qual o custo de novos produtos, o custo de fazer melhorias nos produtos existentes, e o custo de encontrar uma nova forma de produção. A informação da gestão de custos é usada para estabelecer preços, modificar a oferta do produto a fim de aumentar a rentabilidade, modernizar empresas no momento adequado, e determinar novos métodos de vendas e de canais de distribuição.

De acordo com Santos (1987), para que a administração alcance a maximização dos resultados, utilizando-se da análise de custos como instrumento de avaliação de desempenho e de tomada de decisão, os seguintes objetivos básicos deverão ser levados em consideração: custo por produto, resultado de vendas por produto, custo fixo da infra-estrutura instalada, nível mínimo de vendas desejado, formação do preço de venda, planejamento e controle das operações. Este conjunto de elementos da análise de custos é fundamental à gestão dos custos.

Para Matz, Curry e Frank (1987), visto que trabalha com custos, orçamentos e análise de custos, a Contabilidade de Custos pode ser descrita como elemento principal, nas atividades de controle e nas fases de planejamento e de decisões, da empresa. A Contabilidade de Custos fornece à administração registro detalhado, análise e interpretação dos gastos efetuados em conexão com a operação da empresa.

As informações de custos devem ser diferenciadas, dependendo das características particulares de cada empresa. Maher (2001) cita que um dos princípios de contabilidade de custos é que necessidades diferentes muitas vezes exigem informações diferentes. A idéia de "tamanho único" não se aplica em contabilidade de custos.

Shank e Govindarajan (1995) entendem que uma compreensão sofisticada da estrutura de custos de uma empresa pode ir bem longe na busca de uma vantagem 
competitiva sustentável. A análise das informações de custos é relevante para o processo decisório nas organizações, tanto no momento da definição do preço de venda, como na gestão dos custos e em decisões que têm como resultado o incentivo aos produtos mais rentáveis.

Num ambiente cada vez mais competitivo, as organizações são obrigadas a evoluir e apreender constantemente, além de se empenhar na busca de melhores informações para o gerenciamento de seus custos. Desse modo, os gestores de empresas incubadas devem considerar as características da gestão de custos a fim de adequá-las a estrutura física e operacional da empresa. Além disso, devem extrair das análises dos custos o suporte na busca de vantagens competitivas para a empresa.

\section{PROCEDIMENTOS METODOLÓGICOS DA PESQUISA}

Os delineamentos desta pesquisa deram-se em função dos objetivos, dos procedimentos e da abordagem do problema. No tocante à tipologia relacionada aos objetivos, esta pesquisa consiste de um estudo do tipo descritivo. De acordo com Vergara (2000, p. 47), a pesquisa descritiva "expõe características de determinada população ou de determinado fenômeno. Pode também estabelecer correlações entre variáveis e definir sua natureza. Não tem compromisso de explicar os fenômenos que descreve, embora sirva de base para tal explicação".

No que concerne aos procedimentos, refere-se a uma pesquisa survey. Segundo Gil (1999), a pesquisa survey se caracteriza pela interrogação direta das pessoas cujo comportamento se deseja conhecer. Basicamente, procede-se a solicitação de informações a um grupo significativo de pessoas acerca do problema estudado para em seguida, mediante análise quantitativa, obter as conclusões correspondentes aos dados coletados.

A perspectiva do estudo é de corte transversal ou seccional, pois os dados foram coletados em um determinado ponto no tempo, tendo por base uma amostra selecionada para descrever as características da população num momento definido. Richardson (1999) explica que, no corte transversal, identifica-se a população, 
escolhe-se a amostra e realiza-se a pesquisa. O corte desta pesquisa compreendeu o momento do levantamento dos dados, que ocorreu no mês de novembro de 2009.

Quanto à abordagem do problema, refere-se a uma abordagem quantitativa. No que concerne à abordagem quantitativa, Richardson (1999) afirma que se caracteriza pelo emprego de quantificação tanto nas modalidades de coleta de informações, quanto no tratamento delas por meio de técnicas estatísticas, desde as mais simples como percentual, média, desvio-padrão, às mais complexas, como coeficiente de correlação, análise de regressão etc.

A população contituiu-se de 359 incubadoras de empresas brasileiras à Associação Nacional de Entidade Promotoras de Empreendimentos Inovadores (ANPROTEC), conforme relação disponibilizada pela equipe de pesquisa da referida associação. Considerou-se como amostra o retorno dos questionários respondidos por coordenadores de 157 incubadoras brasileiras, representando $43,73 \%$ da população, o que constitui a amostra por acessibilidade.

Para a coleta de dados foi utilizada a técnica de questionários, estruturado com perguntas fechadas e encaminhados aos coordenadores por e-mail. Gil (1999) explicita que o questionário, como instrumento de coleta de dados, é composto de um número mais ou menos elevado de questões apresentadas por escrito às pessoas, tendo como objetivo o conhecimento de suas opiniões, crenças, sentimentos, interesses, expectativas, situações vivenciadas.

A análise dos dados coletados na pesquisa deu-se por meio da abordagem quantitativa. Para tanto, primeiramente as respostas às perguntas do questionário foram digitadas em planilha eletrônica. Na seqüência, utilizou-se a estatística descritiva para organizar, resumir e apresentar os dados estatísticos (STEVENSON, 1981).

\section{DESCRIÇÃO E ANÁLISE DE DADOS}

O estudo sobre a gestão de custos nas empresas incubadas em incubadoras brasileiras, além de proporcionar aprimoramentos para estudos futuros, é importante por não se ter encontrado pesquisas desta natureza realizadas no Brasil. Os dados coletados junto às incubadoras compreenderam aspectos relacionados ao perfil das 
incubadoras pesquisadas, requisitos para a instalação de empreendimentos nas incubadoras, e gestão de custos nas empresas incubadas.

\subsection{Perfil das incubadoras brasileiras pesquisadas}

Antes de proceder à análise do suporte das incubadoras brasileiras na gestão de custos das empresas incubadas, fez-se necessário delinear o perfil destas incubadoras.

\section{a) Localização das incubadoras por região brasileira}

Fez-se o mapeamento das incubadoras por região brasileira, sendo elas: Norte, Nordeste, Centro-Oeste, Sudeste e Sul. A localização das incubadoras por região é demonstrada na Tabela 1.

Tabela 1: Localização das incubadoras por região brasileira

\begin{tabular}{|c|c|c|c|c|}
\hline \multirow{2}{*}{ Região } & \multicolumn{2}{|c|}{ População } & \multicolumn{2}{|c|}{ Amostra } \\
\hline & $\mathrm{n} . \stackrel{0}{ }$ & $\%$ & $\mathrm{n} . \stackrel{\circ}{ }$ & $\%$ \\
\hline Norte & 14 & 3,90 & 9 & 1,91 \\
\hline Nordeste & 63 & 17,54 & 19 & 12,10 \\
\hline Centro-Oeste & 28 & 7,80 & 7 & 4,46 \\
\hline Sudeste & 127 & 35,38 & 52 & 33,12 \\
\hline Sul & 127 & 35,38 & 76 & 48,41 \\
\hline Total & 359 & 100 & 157 & 100 \\
\hline
\end{tabular}

Fonte: Dados da pesquisa (2009).

As regiões com maior representatividade em número de incubadoras são a Região Sul e a Região Sudeste, ambas com 127. Apresentam números menores a Região Nordeste, com 63, Centro-Oeste, com 28, e Norte, com 14.

No que concerne à amostra da pesquisa, a Região Sul apresenta o maior número, com 76 incubadoras; na sequência tem-se a Região Sudeste, com 52; a Nordeste, com 19; a Região Norte, com 9; e a Região Centro-Oeste, com 7. Embora a amostra não tenha sido estratificada por região, há uma certa aderência no número populacional e amostral por região.

b) Responsáveis pela administração das incubadoras 
Depois de constituídas, as incubadoras podem ter sua administração vinculada aos organismos que participaram de sua constituição ou ter uma administração própria. $\mathrm{Na}$ Tabela 2 apresenta-se os responsáveis pela administração das incubadoras.

Tabela 2: Responsáveis pela administração das icubadoras pesquisadas

\begin{tabular}{l|c|c}
\hline \multicolumn{1}{c|}{ Administração das Incubadoras } & \multicolumn{2}{c}{ Frequência } \\
\cline { 2 - 3 } & $\mathrm{n} \cdot \mathbf{0}$ & $\%$ \\
\hline Universidade & 78 & 49,68 \\
\hline Própria & 35 & 22,29 \\
\hline Federação da Indústria & 19 & 12,10 \\
\hline Prefeitura & 11 & 7,01 \\
\hline Outros & 14 & 8,92 \\
\hline Total & 157 & 100 \\
\hline
\end{tabular}

Fonte: Dados da pesquisa (2009).

Verifica-se que $49,68 \%$ das incubadoras são administradas por universidades e 22,29\% possuem administração própria. Na sequência, 12,10\% são administradas pela Federação da Indústria do Estado em que estão situadas; $7,01 \%$ são administradas pela Prefeitura; e 8,92\% possuem outros responsáveis pela administração, como empresas terceirizadas, governo estadual, entre outros.

\section{c) Tipologias de incubadoras}

Quanto às tipologias de incubadoras mais comuns no Brasil, conforme dados levantados na pesquisa, são incubadoras de empresas de base tecnológica, incubadoras de empresas de setores tradicionais e incubadoras mistas. Na Tabela 3 demonstram-se os números de cada tipologia de incubadora, por região. 
Tabela 3: Ramo de atuação das incubadoras estudadas por região brasileira

\begin{tabular}{l|c|c|c|c|c|c}
\hline \multirow{2}{*}{\multicolumn{1}{c|}{ Região }} & \multicolumn{6}{c}{ Tipologia de Incubadora } \\
\cline { 2 - 8 } & Base Tecnológica & \multicolumn{2}{c}{ Tradicional } & \multicolumn{2}{c}{ Mista } \\
\cline { 2 - 8 } & n. - & $\%$ & n. & $\%$ & n. & $\%$ \\
\hline Norte & 2 & 1,89 & 1 & 2,94 & 0 & 0,00 \\
\hline Nordeste & 14 & 13,21 & 3 & 8,82 & 2 & 11,76 \\
\hline Centro-Oeste & 4 & 3,77 & 2 & 5,88 & 1 & 5,88 \\
\hline Sudeste & 41 & 38,68 & 8 & 23,53 & 3 & 17,65 \\
\hline Sul & 45 & 42,45 & 20 & 58,83 & 11 & 64,71 \\
\hline Total & 106 & 100 & 34 & 100 & 17 & 100 \\
\hline
\end{tabular}

Fonte: Dados da pesquisa (2009).

Nas incubadoras pesquisadas, a tipologia que apresenta maior número é a de base tecnológica, com 106 incubadoras. Estas estão assim distribuídas, 42,45\% na Região Sul, 38,68\% na Região Sudeste, $13,21 \%$ na Região Nordeste e 3,77\% na Região Centro-Oeste.

As incubadoras tradicionais, em número de 34 , se caracterizam como organizações que abrigam empreendimentos ligados aos setores da economia que detém tecnologias largamente difundidas e que queiram agregar valor aos seus produtos, processos ou serviços, por meio de um incremento em seu nível tecnológico, 20 estão localizadas na Região Sul, 8 na Região Sudeste, 3 na Região Nordeste, 2 na Região Centro-Oeste e 1 na Região Norte. Entre as incubadoras mistas, que se caracterizam como organizações que abrigam ao mesmo tempo empresas de base tecnológica e empresas de setores tradicionais, 11 estão localizadas na Região Sul, 3 na Região Sudeste, 2 na Região Nordeste e 1 na Região Centro-Oeste.

\subsection{Requisitos para instalação de empreendimentos nas incubadoras}

Cumprir os requisitos necessários para a instalação de empreendimentos nas incubadoras é um dos primeiros desafios aos empreendedores que buscam no processo de incubação o suporte necessário para o crescimento do negócio. Neste contexto, é importante identificar os requisitos necessários para a instalação de empreendimentos nas incubadoras brasileiras. $\mathrm{Na}$ Tabela 4 apresentam-se os 
fatores indicados como elementos de análise na seleção de empresas para incubação pelas incubadoras.

Tabela 4: Fatores analisados na seleção de empresas candidatas ao processo de incubação

\begin{tabular}{l|c|c}
\hline \multirow{2}{*}{ Fatores Analisados } & \multicolumn{2}{c}{ Frequência } \\
\cline { 2 - 3 } & $\mathrm{n} .{ }^{\circ}$ & $\%$ \\
\hline Viabilidade do negócio & 145 & 25,17 \\
\hline Características inovadoras do produto & 132 & 22,92 \\
\hline Tecnologia do produto & 123 & 21,35 \\
\hline Perfil do empreendedor & 81 & 14,06 \\
\hline Setor de atuação do empreendimento & 22 & 3,82 \\
\hline Experiência do empreendedor no setor de atuação & 14 & 2,43 \\
\hline Geração de emprego & 9 & 1,56 \\
\hline Processo de produção não-poluente & 8 & 1,39 \\
\hline Idoneidade comercial e pessoal do proponente & 8 & 1,39 \\
\hline Importância da empresa no apoio às empresas já instaladas & 6 & 1,04 \\
\hline Possibilidade de interação com a universidade & 5 & 0,87 \\
\hline Retorno financeiro do empreendimento & 5 & 0,87 \\
\hline Outros fatores & 18 & 3,13 \\
\hline Total & 576 & 100 \\
\hline
\end{tabular}

Fonte: Dados da pesquisa (2009).

Nota: O número de indicações evidenciado é superior a amostra, uma vez que a incubadora pode considerar mais de um fator no processo de seleção.

Observa-se que viabilidade do negócio é o fator com maior freqüência, apresentando $25,17 \%$ de indicação pelos respondentes. Não foi objeto deste estudo verificar quais critérios as incubadoras utilizam no processo de análise de viabilidade do negócio. Na sequência, tem-se características inovadoras do produto, com $22,92 \%$. Seguem-se tecnologia do produto, com 21,35\%; perfil do empreendedor, com 14,06\%; setor de atuação do empreendimento, com 3,82\%; experiência do empreendedor no setor de atuação, com 2,43\%; geração de empresa, com 1,56\%, e processo de produção não-poluente e idoneidade comercial e pessoal do proponente, ambas com 1,39\%. Em proporções bem menores estão os demais fatores considerados.

O item outros fatores contempla os seguintes critérios: adequação do empreendimento aos objetivos da incubadora, capacidade do empreendedor em assumir riscos, possibilidade de divulgação do nome da incubadora no produto, sinergia da equipe, compatibilidade dos recursos a serem aplicados em relação ao 
negócio, autonomia gerencial, equipe técnica envolvida.

A fase de seleção é importante não só para identificar a viabilidade do empreendimento e as capacidades do empreendedor, mas também selecionar empresas cujo suporte administrativo, financeiro e de estrutura disponibilizado pela incubadora possam favorecê-las.

Os empreendedores devem analisar critérios específicos utilizados pelas incubadoras na seleção de empresas candidatas ao processo de incubação, a fim de verificar se esses coadunam com suas características. Cumpridos estes requisitos e selecionado pela incubadora, o empreendimento tem a oportunidade de desenvolver-se mediante um conjunto de suportes colocados à sua disposição, dentre eles o suporte na gestão de custos.

\subsection{Gestão de custos das empresas incubadas}

O suporte disponibilizado pelas incubadoras aos empreendedores faz parte do processo de gestão das empresas incubadas. A partir desse suporte, os empreendedores ampliam seus conhecimentos e aprendem a gerenciar o negócio. O suporte na gestão de custos faz parte de um conjunto de suportes oferecidos pelas incubadoras brasileiras aos incubados, condição necessária para o processo de avaliação de estoques, controle e tomada de decisões dos empreendimentos. A Tabela 5 mostra a ocorrência de cada tipo de programa oferecido às empresas incubadas nas diferentes fases do processo de incubação. 
Tabela 5: Programas oferecidos nas diferentes fases do processo de incubação

\begin{tabular}{|c|c|c|c|c|c|c|c|c|c|c|}
\hline \multirow{3}{*}{ Tipo de Suporte } & \multicolumn{10}{|c|}{ Fases do Processo de Incubação } \\
\hline & \multicolumn{2}{|c|}{ 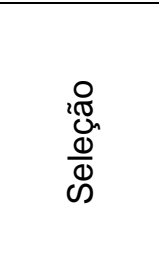 } & \multicolumn{2}{|c|}{ 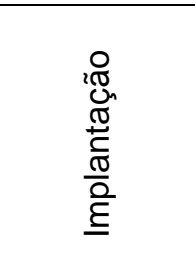 } & \multicolumn{2}{|c|}{ 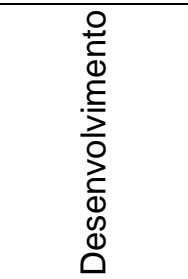 } & \multicolumn{2}{|c|}{ 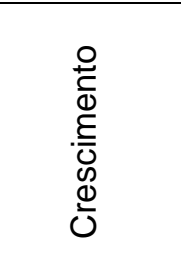 } & \multicolumn{2}{|c|}{ 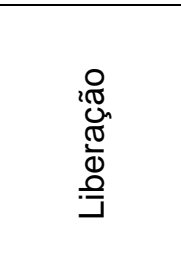 } \\
\hline & n.. & $\%$ & n.. & $\%$ & ก. ${ }^{\circ}$ & $\%$ & n.. & $\%$ & n.. & $\%$ \\
\hline $\begin{array}{l}\text { Capacitação (cursos internos e } \\
\text { externos) }\end{array}$ & 0 & 0 & 8 & 47,06 & 112 & 43,92 & 123 & 44,40 & 23 & 20,72 \\
\hline Participação em eventos & 0 & 0 & 5 & 29,41 & 90 & 35,29 & 78 & 28,16 & 12 & 10,81 \\
\hline Disponibilização de tecnologias & 0 & 0 & 4 & 23,53 & 53 & 20,78 & 76 & 27,44 & 76 & 68,47 \\
\hline Total & 0 & 0 & 17 & 100 & 255 & 100 & 277 & 100 & 111 & 100 \\
\hline
\end{tabular}

Fonte: Dados da pesquisa (2009).

Nota: O número de indicações evidenciado é superior a amostra, uma vez que o respondente pode considerar mais de um tipo de suporte em cada fase de incubação.

Os resultados mostram que na fase de seleção não há ocorrência de qualquer tipo de programa na gestão de custos das empresas incubadas. Apesar da ausência de ocorrência, é provável que muitas incubadoras auxiliem os candidatos à incubação na elaboração do plano de negócios, envolvendo informações relacionadas aos custos. Os custos estimados no plano de negócios interferem na viabilidade do empreendimento, sendo este o item mais apontado enquanto fator analisado no processo de seleção, conforme Tabela 4.

$\mathrm{Na}$ fase de implantação, a capacitação (cursos internos e externos) foi o tipo de programa que recebeu o maior número de indicações, com 47,06\%. Na sequência, com 29,41\%, a participação em eventos e, com 23,53\%, a disponibilização de tecnologias. Nas fases de desenvolvimento e crescimento houve comportamento semelhante a fase anterior. Na fase de liberação, em que a empresa esta prestes a atuar sozinha no mercado, a frequência de suporte mostrou comportamento adverso das fases anteriores. Foi indicado com maior frequência, nesta fase, disponibilização de tecnologias, com 68,47\%. Após, com 20,72\%, capacitação (cursos internos e externos) e, 10,81\%, disponibilização de tecnologias.

Também foi objeto de questionamento a existência ou não de formalização dos controles de custos por parte das empresas incubadas. Das 157 incubadoras brasileiras que retornaram o questionário respondido, 24,20\% (38 incubadoras) 
indicaram que as empresas incubadas possuem formalização do controle de custos. Aos coordenadores que responderam de maneira afirmativa, foi solicitado na próxima questão o tipo de formalização do controle de custos utilizado pelas empresas incubadas. Os resultados são apresentados na Tabela 6.

Tabela 6: Tipos de formalização do controle de custos

\begin{tabular}{l|c|c}
\hline \multicolumn{1}{c|}{ Itens } & \multicolumn{2}{c}{ Frequência } \\
\cline { 2 - 3 } & $\mathrm{n} .{ }^{\circ}$ & $\%$ \\
\hline Identificação periódica dos gastos incorridos & 35 & 41,67 \\
\hline Controle de materiais por meio de fichas de estoque & 27 & 32,14 \\
\hline Técnicas de apropriação dos custos indiretos & 15 & 17,86 \\
\hline Estimativas de custos & 7 & 8,33 \\
\hline Total & 84 & 100 \\
\hline
\end{tabular}

Fonte: Dados da pesquisa (2009).

Nota: O número de indicações evidenciado é superior a amostra, uma vez que o respondente pode considerar mais de um tipo de formalização do controle de custos.

Verifica-se que o tipo de formalização do controle de custos mais utilizado é a identificação periódica dos gastos incorridos, com 41,67\%. Após, tem-se controle de materiais por meio de fichas de estoque, com 32,14\%; técnicas de apropriação dos custos indiretos, com $17,86 \%$; e estimativas de custos, com $8,33 \%$.

Sabendo-se que alguns respondentes indicaram mais de um tipo de formalização do controle de custos, infere-se que as empresas incubadas nestas incubadoras possuem controles de custos consideravelmente acurados quando comparados com muitas empresas que atuam no mercado há vários anos. Esses dados confirmam a importância do processo de incubação para a sobrevivência dos empreendimentos incubados quando passam a atuar no mercado sem o suporte da incubadora.

Questionou-se também os processos considerados na estruturação dos custos dos produtos. Independentemente da formalização ou não do controle de custos, a partir dos processos realizados são incorridos gastos que devem ser considerados na estrutura dos custos das empresas incubadas. Na Tabela 7 são apresentados os resultados obtidos. 
Tabela 7: Processos considerados na estruturação dos custos

\begin{tabular}{l|c|c}
\hline \multirow{2}{*}{ Processos } & \multicolumn{2}{c}{ Freqüência } \\
\cline { 2 - 3 } & n. $^{\circ}$ & $\%$ \\
\hline Desenvolvimento & 67 & 33,00 \\
\hline Comercial & 55 & 27,09 \\
\hline Produção & 50 & 24,63 \\
\hline Gerencial & 23 & 11,33 \\
\hline Outros & 8 & 3,94 \\
\hline Total & 203 & 100 \\
\hline
\end{tabular}

Fonte: Dados da pesquisa (2009).

Nota: O número de indicações evidenciado é superior a amostra, uma vez que o respondente pode considerar mais de um processo na estruturação dos custos.

Os resultados apresentados na Tabela 7 evidenciam que o processo mais considerado pelas empresas incubadas na estruturação dos custos é o desenvolvimento, com $33,00 \%$. Os processos comercial e produção também apresentaram posição de destaque, com $27,09 \%$ e $24,63 \%$, respectivamente. Já o processo gerencial representa $11,33 \%$ do total de indicações.

Entende-se que os resultados obtidos coadunam com a característica dos empreendimentos abrigados pelas incubadoras, cujo grau de incorporação tecnológica normalmente é representativo. A inserção de ingredientes tecnológicos requer gastos com pesquisa e desenvolvimento, de novos produtos ou de aperfeiçoamento nos produtos já existentes.

Para melhor caracterização da identificação dos custos pelas empresas incubadas, solicitou-se a forma como as mesmas fazem tal identificação. Os resultados obtidos são apresentados na Tabela 8. 
Tabela 8: Identificação dos custos

\begin{tabular}{l|c|c}
\hline \multirow{2}{*}{ Formas de Identificação } & \multicolumn{2}{c}{ Frequência } \\
\cline { 2 - 3 } & n.o & $\%$ \\
\hline Unidade de produto & 140 & 50,54 \\
\hline Centros de custos & 56 & 20,22 \\
\hline Departamentos & 45 & 16,25 \\
\hline Atividades & 15 & 5,42 \\
\hline Processos & 12 & 4,33 \\
\hline Outros & 9 & 3,25 \\
\hline Total & 277 & 100 \\
\hline
\end{tabular}

Fonte: Dados da pesquisa (2009).

Nota: O número de indicações evidenciado é superior a amostra, uma vez que o respondente pode considerar mais de um tipo de identificação.

Quanto às formas utilizadas, $50,54 \%$ das indicações correspondem a unidade de produto. A identificação dos custos por meio de centros de custos e departamentos representam, respectivamente, $20,22 \%$ e $16,25 \%$ das indicações. Em proporções menores, atividades com $5,42 \%$ e processos com $4,33 \%$ das indicações.

Pesquisaram-se também os tipos de decisões que utilizam as informações de custos. A Tabela 9 evidencia as decisões empresariais com as respectivas frequências.

Tabela 9: Utilização das informações de custos em decisões empresariais

\begin{tabular}{l|c|c}
\hline \multicolumn{1}{c|}{ Fatores Analisados } & \multicolumn{2}{c}{ Frequência } \\
\cline { 2 - 3 } & $\mathrm{n} .{ }^{-0}$ & $\%$ \\
\hline Vendas & 107 & 25,54 \\
\hline Lucratividade por produto & 79 & 18,85 \\
\hline Projeto do produto & 52 & 12,41 \\
\hline Lucratividade por cliente & 41 & 9,79 \\
\hline Gerenciamento das atividades & 33 & 7,88 \\
\hline Avaliação de desempenho & 29 & 6,92 \\
\hline Relacionamento com clientes & 22 & 5,25 \\
\hline Canais de distribuição & 18 & 4,30 \\
\hline Segmentação de mercado & 16 & 3,82 \\
\hline Reengenharia dos processos de negócio & 13 & 3,10 \\
\hline Outros & 9 & 2,15 \\
\hline Total & 419 & 100 \\
\hline
\end{tabular}

Fonte: Dados da pesquisa (2009). 
Nota: O número de indicações evidenciado é superior a amostra, uma vez que o respondente pode considerar mais de um tipo de decisão.

$\mathrm{Na}$ análise das decisões empresariais, as decisões de vendas obtiveram o maior número de indicações, com $25,54 \%$. Na sequência tem-se lucratividade por produto, com 18,85\%; projeto do produto, com 12,41\%; lucratividade por cliente, com 9,79\%; gerenciamento das atividades, com 7,88\%; e avaliação de desempenho, com 6,92\%. Em números menores foram indicadas as seguintes decisões: relacionamento com clientes, canais de distribuição, segmentação de mercado, e reegenharia dos processos de negócios.

\section{CONSIDERAÇÕES FINAIS}

O estudo objetivou investigar o suporte das incubadoras brasileiras na gestão de custos das empresas incubadas. Pesquisa descritiva foi realizada por meio de uma survey nas 359 incubadoras brasileiras e a amostra por acessibilidade compreendeu as 157 incubadoras que responderam o questionário.

Pela análise dos dados coletados, constatou-se que as incubadoras brasileiras disponibilizam suporte na gestão de custos das empresas incubadas por meio de capacitação (cursos internos e externos), participação em eventos e disponibilização de tecnologias. $\mathrm{Na}$ fase de seleção não houve indicação de disponibilização deste tipo de suporte. Nas fases de implantação, desenvolvimento e crescimento, o suporte mais disponibilizado é a capacitação (cursos internos e externos). Na fase de liberação, a disponibilização de tecnologias foi o suporte mais indicado.

Observou-se também, que a minoria das empresas incubadas possui formalização dos controles de custos. Entre as empresas que possuem, o tipo de formalização mais utilizado é a identificação periódica dos gastos incorridos, e o menos utilizado são as estimativas de custos. Alguns respondentes indicaram mais de um tipo de formalização de controle de custos.

Dentre os processos considerados na estruturação dos custos, o processo mais considerado é o desenvolvimento. O processo gerencial, apesar de importante no processo decisório, não ocupou posição de destaque. Os processos comercial e 
produção também foram destacados pelos respondentes. Os custos incorridos a partir dos processos serão identificados pelas empresas incubadas de diferentes formas.

Quanto às formas de identificação de custos utilizadas, a unidade de produto correspondeu a maioria das indicações. Em proporções menores foram indicadas as atividades e os processos. No que diz respeito à utilização das informações de custos em decisões empresariais, as decisões de vendas obtiveram o maior número de indicações. Na sequência tem-se lucratividade por produto, projeto do produto, lucratividade por cliente, gerenciamento das atividades, e avaliação de desempenho. Em números menores foram indicadas as seguintes decisões: relacionamento com clientes, canais de distirbuição, segmentação de mercado, e reegenharia dos processos de negócios.

\section{REFERÊNCIAS}

AMATO NETO, J. Redes de cooperação produtiva e clusters regionais: oportunidades para as pequenas e médias empresas. São Paulo: Atlas e Fundação Vanzolini, 2000.

ASSOCIAÇÃO Nacional de Entidades Promotoras de Empreendimentos Inovadores - ANPROTEC. Incubadora de empresas. Disponível em: $<$ http://www.anprotec.org.br>. Acesso em: 13 jan. 2010.

BAÊTA, A. M. C. O desafio da criação: uma análise das incubadoras de empresas de base tecnológica. Petrópolis: Vozes, 1999.

BLOCHER, Edward J.; CHEN, Kung H.; COKINS, Gary; LIN, Thomas W. Gestão estratégica de custos. São Paulo: McGraw-Hill, 2007.

DORNELAS, J. C. A. Planejando incubadoras de empresas: como desenvolver um plano de negócios para incubadoras. Rio de Janeiro: Campus, 2002.

FONSECA, Sérgio Azevedo; KRUGLIANSKAS, Isak. Avaliação do desempenho de incubadoras empresariais mistas: um estudo de caso no Estado de São Paulo, Brasil. In: IASP - CONFERÊNCIA LATINOAMERICANA DE PARQUES TECNOLÓGICOS E INCUBADORAS DE EMPRESAS, 2000, Panamá. Anais... Panamá: IASP, 2000. CD ROM.

GIL, Antônio Carlos. Métodos e técnicas de pesquisa social. São Paulo: Atlas, 1999. 
HACKETT, Sean M.; DILTS, David M. A systematic review of business incubation research. Journal of Technology Transfer, Netherlands, v.29, p. 55-82, 2004.

MAHER, Michael. Contabilidade de custos: criando valor para a administração. São Paulo: Atlas, 2001.

MARTINS, Eliseu. Contabilidade de custos. São Paulo: Atlas, 2003.

MATZ, Adolf; CURRY, Othel J.; FRANK, George W. Contabilidade de custos. São Paulo: Atlas, 1987.

MEGLIORINI, Evandir. Custos: análise e gestão. São Paulo: Pearson Prentice Hall, 2007.

PORTER, Michael E. Vantagem competitiva: criando e sutentado um desempenho superior. Rio de Janeiro: Campus, 1989.

RICHARDSON, Roberto Jarry. Pesquisa social: métodos e técnicas. São Paulo: Atlas, 1999.

SANTOS, Joel José dos. Análise de custos: um enfoque gerencial. São Paulo: Atlas, 1987.

SHANK, John K; GOVINDARAJAN, Vijay. Gestão estratégica de custos: a nova ferramenta para a vantagem competitiva. Rio de Janeiro: Campus, 1995.

STEVENSON, W. J. Estatística aplicada à administração. São Paulo: Harper \& Row do Brasil, 1981.

VEDOVELLO, Conceição; FIGUEIREDO, Paulo N. Incubadora de inovação: que nova espécie é essa? Revista de Administração de Empresas Eletrônica, São Paulo, v.4, n.1, jan./jun. 2005.

VERGARA, Sylvia Constant. Projetos e relatórios de pesquisa em administração. 3. ed. São Paulo: Atlas, 2000. 